\title{
Fundamental Aspects of Erosion
}

\author{
By Dr. E. G. Richardson, King's College, Newcastle-on-Tyne
}

$\mathrm{E}^{\mathrm{R}}$ ROSION is a problem of considerable complexity which cannot readily be expressed in terms of known physical laws. Up to the present, it has lain mainly in the sphere of the engineer, who has evolved a number of empirical laws for predicting its magnitude. It is evident by the disagreement not merely in coefficients but even in the functions on which the erosion is made to depend, that these rules are designed only to fit the conditions which fall within the experience of particular engineers and have no universal application. Before further progress can be made in combating the evil, one must attempt to reduce the problem to its simplest proportions.

Pioneer fundamental research in the subject was carried out by Gilbert in 1914 in America, while recently Hjulstrom* in Sweden and I myself $\dagger$ in Great Britain have independently carried out laboratory and field experiments in which the question has been studied under conditions which reduce the variable quantities to a minimum. The factors which then remain can be grouped under two headings: first, those which concern the eroding stream-whether it is in steady motion or turbulent and in particular the value of the gradient of stream velocity at the surface of the soil ; secondly, the nature of the soil bed, the size, shape and density of the grains and whether they are closely or loosely compacted.

In field experiments, all these factors intervene in a fashion which does not allow of the separation of their respective contributions. It is desirable, as a basis for establishing the laws of erosion, to make experiments first in artificial channels, using a bed of loosely compacted and nearly homogeneous particles so that the factors just enumerated can be varied one at a time. Measurements are then made of the mean quantity of silt transported at various heights above the bed and of the gradient of mean velocity transverse to the stream in the same vertical section. I have made such observations in a glass-sided channel having a wooden floor on which a bed of sand, graded within fine limits by sieving, was laid. The velocity of the stream along the channel was measured from point to point by a hot-wire anemometer, while

\footnotetext{
* Bull. Geol. Inst. Uppsala, 25, 221 (1935). This paper contains a bibliography of erosion. Other more recent accounts of (gross) silt transport will be found in Water Pollution Research, Tech. Paper No. 7 (1937); U.S. Waterways Expt. Stat. Paper No. 17; U.S. Geol. Survey Water Supply Paper No. 797; Y. L. Chang, Proc. Amer. Soe. Civ. Eng., Nov. (1937).

†Phil. Mag., 17, 769 (1934); Proc. Roy. Soc., A, 162, 583 (1937).
}

the silt concentration at any level was measured photo-electrically in terms of the absorption which a narrow beam of light cast athwart the stream suffered in virtue of the intervening sand carried in suspension. Although the experiments were actually carried out in water, there is no essential difference between the behaviour of air and water in this respect, due regard being paid to their relative viscosities and to the relative buoyancies of the eroded material in the two media.

The disturbing influence on the soil which lifts the grains into the stream is in the main due to the shear on it, that is, the product of viscosity and the velocity gradient at the bed, while the restoring force is determined by the natural rate of sinking of the grains. Under the combined action of erosion and gravitational force, the grains are so distributed that the silt concentration at any level fluctuates about a mean the value of which falls off exponentially with height, at least over the major part of any vertical section. If the bed be changed for one of coarser but still homogeneous particles, the exponent in this relation and with it the total quantity of silt carried in suspension diminishes in consequence of the faster rate of free fall of such particles. If then one plots the height against the logarithm of the silt concentration, a line is obtained which is almost straight (except near the bed) and the slope of which can be taken as a measure of the erosion coefficient. For a given velocity gradient, provided the stream is sufficiently turbulent to afford adequate mixing, this coefficient is found to be inversely as the grain size, bearing out theory in this respect.

Similar considerations apply in natural streams, where the bed, of course, is not homogeneous. Samples taken out of the River Tyne in flood at various depths and analysed in respect of sizefrequency give a series of curves the mean slope of which for each size follows the same law. Occasionally it is reported by hydraulic engineers (who measure in terms of surface velocity and slope of bed) that 'colloidal' particles are less easily eroded than somewhat larger ones, so that in a mixed bed there is maximum rate of erosion occurring for a diameter round about one tenth of a millimetre. This anomaly is usually attributed to the superior cohesion which a clay sludge possesses. The exception, however, disappears if one reckons erosion in terms of the velocity 
gradient instead of surface velocity, for it is well known that the distribution of velocity across a stream carrying finely divided or colloidal material is not the same as that in homogeneous fluids, or in those in which large crumbs of sparsely distributed soil are in suspension.

The extent to which the soil allows the fluid to permeate it has probably the most important influence in loosening the bed prior to actual erosion. When water passes over the soil a certain amount of chemical action may take place, particularly when the surface soil is a limestone formation, but whether this occurs or not, once the water is able to break up the soil into smaller crumbs or to encircle those which already existed before its passage, it can exert pressure to move the formerly coherent grains, which then become potential silt. Sometimes an actual lifting force may be exerted, that is to say, the line of action of the pressure may be inclined upwards instead of along the bed. This happens notably when a grain is lying a little higher than its fellows on the bed and its foundations are partially or completely undermined by the fluid. The local velocity at the top of the grain is then greater than that beneath, so that the force towards the underside may exceed the total of gravity and the downward force on the top. Such a state of affairs often occurs where a pebble is resting on a sandy bottom, and the resultant force may lift it momen-

tarily into the body of the stream. As soon, however, as it has risen above the boundary layer of fluid in which the major part of the gradient of velocity is found, the lift is lost and it sinks back.

This accounts for the series of long hops by which the heavier particles follow the stream and the ultimate formation of ridges or dunes, but this process does not, in my observation, contribute markedly to the silt load of the stream itself, which is a function merely of the degree of turbulence, velocity gradient and grain size. Penetration of the soil by the eroding fluid can nevertheless change the distribution of velocity near the bedin fact, at a sandy bottom the gradient of velocity may show a point of inflection separating the domain of quasi-fluid motion above and quasi-solid flow below-and in this way react on the silt load carried in suspension.

How, then, do the means commonly adopted for the prevention of erosion stand in the light of these results? Attempts to lower the overall slope of the land by farming on the terrace system or by obstructions in the form of vegetation would seem to be but partial palliatives, at least so far as water action is concerned, since when the waterlevel is low the gradient at the bed may still be large, while if the water-level is high over soil of small permeability and the slope or obstruction is effective in keeping down the erosion coefficient, it will hold up the run-off and leave the land waterlogged. What the water engineer requires is a system which will keep the shearing force on the bed small, while not unduly impeding the run-off above. In the case of a river, this desideratum may be secured by a series of check dams or shallow weirs placed at short intervals across its bed. In this way the stream goes down a shallow staircase ; 
employed an apparatus for this purpose in the Tyne at Newcastle consisting of a pair of light beams and photo-electric cells placed at one third and two thirds of the depth below the surface, the mean flow being measured at the same time on a meter of the rotating vane type. Hjulstrom has made measurements to the same end by actual weighing of silt samples taken out of the River Fyris at Uppsala. It is really surprising what large silt loads can be carried annually by comparatively sluggish rivers. Thus Hjulstrom estimates that the Fyris-normally quite translucent-carries away more than 60,000 tons of material-soluble and insoluble-from its basin every year past the bridge at Uppsala. The figure for the more turbid and fast-running Tyne has not been precisely estimated; but it is considerably in excess of this.

\section{Research in Freshwater Biology in Great Britain}

$\mathrm{T}$ HE need for a biological station for research on problems connected with freshwaters was emphasized at the meeting of the British Association at Glasgow in 1928, and this led to the foundation of the Freshwater Biological Associa. tion of the British Empire in 1929. Two more years of active work on the part of the many men of science and others interested in the project elapsed before the laboratory was founded at Wray Castle on the shores of Windermere in 1931. At first there were but two members of staff, making the best of a few rooms without laboratory fittings, but from 1931 until the present year progress has been rapid, as is well shown by the recently issued sixth annual report*.

The whole of Wray Castle is now occupied, there being on the ground-floor seven laboratories, fitted with adequate benches, sinks, electric light, power and gas, and upstairs a library, offices, and a number of living rooms capable of housing the unmarried members of the staff and up to a dozen scientific visitors. There are now seven resident scientific investigators: Dr. E. B. Worthington (director), five assistant naturalists, and a bacteriologist, who cover all the major branches of the subject. These, together with secretarial and laboratory staff, should place Wray Castle among the foremost freshwater biological stations in the world, and make it capable of carrying out work of national importance.

The interests most closely concerned with freshwater biology may be grouped into three categories-academic research, fisheries and watersupply-and each contributes materially to the finances of the Association. Accordingly, some limit has to be put to the scope of the work which is undertaken, those subjects being chosen which are likely to elucidate the factors which control the production of life, both qualitative ànd quantitative. The extent and variety of waters within easy reach of Wray Castle give ample scope for work on the many subjects involved.

- The Freshwater Biological Association of the British Empire. Sixth Annual Report for the Year ending March 31st, 1938. Price to nonmembers, $1 s$.
One promising line followed up during the past twelve months is connected with the bottom deposits of lakes. With the co-operation of the Hydrographic Department of the Admiralty, a detailed bathymetric survey was made of Windermere by the new supersonic echo-sounding method. The records revealed not only the depth of water but also the thickness of soft deposits overlying the glacial basin. In addition, cores of the deposits have been obtained and appear to reveal a succession of cold and warm phases during the early history of the lake, so that a good opportunity exists for adding to knowledge of the post-glacial history of the district. This research has more than historical significance because the use of the echo-sounding machine to demonstrate the thickness of soft deposits below a considerable depth of water has an immediate application to reservoirs, where the accumulation of mud may lead to greater production of algæ, and other troubles in filtration and purification of water for domestic purposes.

Work in past years by Prof. W. H. Pearsall, Mr. R. Misra and others has demonstrated the great importance of the character of bottom muds in controlling the chemical (especially nitrogen) balance, and also the plant and animal associations. Here an investigation at Wray Castle on the bacteriology of lakes, streams and bottom deposits, which is being financed by the Department of Scientific and Industrial Research, may be very significant. Attention will be devoted by Dr. C. B. Taylor, who has been appointed to the new post, primarily to the part played by bacteria in the nitrogen and phosphorus cycles Closely linked with this is Dr. C. H. Mortimer's work on the chemical budget of a whole drainage basin. This has involved routine chemical analyses and the measurement of water-flows of rivers throughout the year, in order to estimate the quantity of different salts entering and leaving Windermere. The effect of chemical factors on the growth of algæ is studied by Dr. M. Rosenberg by correlating the quality and quantity of algæ, as observed in natural conditions, with the chemical 